\title{
Neurointerventional Research between 2003 and 2012: Slow Growth, High Interdisciplinary Collaboration, and a Low Level of Funding
}

\author{
J.Y. Lee, D.Y. Yoon, S.D. Yoon, S.A. Nam, and B.M. Cho
}

\begin{abstract}
BACKGROUND AND PURPOSE: Neurointerventional therapy of cerebrovascular disease is a greatly expanding field across many specialty disciplines. The goal of this study was to analyze the characteristics and trends of scientific publications that focused on neurointervention during the past decade.
\end{abstract}

MATERIALS AND METHODS: A bibliometric evaluation of neurointerventional research published between 2003 and 2012 was conducted by using the PubMed data base. Analyzed parameters included the year of publication, type of document, language of the article, topic, declared funding, country of origin, type of collaboration between disciplines, the first author's specialty, and subject category and the Impact Factor of the publishing journal.

RESULTS: Between 2003 and 2012, a total of 2123 articles were published, of which 1107 (52.1\%) were original articles, 1948 (91.8\%) were written in English, 192 (9.0\%) received funding, 661 (31.1\%) were published by the United States, and 1060 (49.9\%) resulted from interdisciplinary collaboration. Neurosurgery departments produced the most articles ( $n=910,42.9 \%)$, followed by radiology $(n=747,35.2 \%)$ and neurology ( $n=270,12.7 \%$ ). The time-trend analysis in the number of publications demonstrated slow growth from 2003 to 2012 , with an average annual growth rate of $+6.0 \%$.

CONCLUSIONS: The fields of neurosurgery, radiology, and neurology have contributed substantially to neurointervention research. Slow growth, high interdisciplinary collaboration, and a low level of funding are peculiar characteristics of research in this field.

ABBREVIATION: IF = Impact Factor

C erebrovascular disease (stroke) is the second leading cause of death worldwide after ischemic heart disease. According to the most recent World Health Organization data, deaths from cerebrovascular disease were an estimated 6.2 million in $2011 .^{1}$ Conservative and surgical treatment has been the standard. In recent years, however, cerebral endovascular treatment (neurointervention) has become a useful therapeutic option for patients with cerebrovascular disease. ${ }^{2}$

Bibliometric analysis is a quantitative method of evaluating scientific productions for different authors, countries, journals, and publications related to a specific topic. ${ }^{3}$ Many investigators from various disciplines have published articles on neurointervention, reflecting the broader application of the techniques to a

Received January 1, 2014; accepted after revision March 12.

From the Departments of Neurosurgery (J.Y.L., S.D.Y., S.A.N., B.M.C.) and Radiology (D.Y.Y.), Kangdong Seong-Sim Hospital, Hallym University College of Medicine, Seoul, South Korea.

Please address correspondence to Dae Young Yoon, MD, Department of Radiology, Kangdong Seong-Sim Hospital, Hallym University College of Medicine, 445 Gil-dong Kangdong-Gu, Seoul, 134-701, Korea; e-mail: evee0914@chol.com

http://dx.doi.org/10.3174/ajnr.A3994 wider variety of cerebrovascular conditions. To our knowledge, however, there has been no bibliometric analysis of characteristics and trends of research within the field.

We performed a bibliometric analysis of the characteristics and trends of scientific publications that focused on neurointervention during the past decade.

\section{MATERIALS AND METHODS}

This study was a retrospective analysis of a publicly available data base and was exempt from institutional review board approval.

\section{Article Search}

The PubMed data base of the National Library of Medicine (www.ncbi.nlm.nih.gov/Pubmed) was used as the primary source of data for this study. The search strategy was built by inputting first the following anatomic terms: "central nervous system" in [Medical Subject Heading Major Topic], carotid, cerebral, cerebellar, basilar, vertebral, or communicating artery in [Title/Abstract]; and second, the following procedural terms: angioplasty, embolisation ${ }^{\star}$, embolization ${ }^{\star}$, endovascular, intra-arterial therapy, neuroendovascular, neurointervention ${ }^{\star}$, recanalize $^{\star}$, stroke 
therapy, thrombectomy, thromboly ${ }^{\star}$, balloon ${ }^{\star}$, coil ${ }^{\star}$, flow diverter*, or stent ${ }^{*}$ in [Title/Abstract]. We limited the period of publication from 2003 to 2012, and we downloaded the data on July 26, 2013. This search resulted in 14,859 publications.

We restricted our analysis to research that was directly related to endovascular treatment for cerebrovascular disease. Therefore, articles on interventional procedures of the common carotid artery, cervical portion of the internal carotid artery, external carotid artery, or aorta $(n=9347)$; and articles related to the pathophysiology, hemodynamics, imaging, conservative management, and surgery of cerebrovascular disease $(n=3239)$ were excluded. Moreover, some types of documents (eg, editorial materials, letters, commentary, and author's reply) $(n=30)$; articles for which the full text was not available from on-line or off-line sources $(n=$ 71); articles that were e-published ahead of print, but not yet included in a finalized printed issue from 2003 to $2012(n=31)$; and articles for which the authors' specialties were not clear $(n=$ 18) were also excluded. Therefore, 2123 articles were finally included in our study.

\section{Parameters Evaluated}

For the analysis, the following information was obtained from each article: 1) year of publication, 2) type of document (original article, case report, review, or technical note), 3) language of the article, 4) topic (endovascular treatment of aneurysm, stent or angioplasty for vascular stenosis, endovascular treatment of arteriovenous malformation or arteriovenous fistula, thrombolysis or thrombectomy, vasospasm, tumor embolization, or miscellaneous), 5) declared funding, 6) country of origin, 7) type of collaboration between disciplines (no collaboration, corresponding author from other department, or coauthors from other department), 8) the first author's specialty (neurosurgery, radiology, neurology, or miscellaneous specialties), and 9) subject category (neuroscience journal, radiology journal, or others) and the Impact Factor (IF) of the publishing journal. We also evaluated the relationships between the first author's specialty and evaluated parameters.

Original articles were defined as reports that investigated clearly stated objectives or hypotheses and contained specifically articulated methods and results sections. If information about the authors' departments was not available or was ambiguous (such as Department of Neurologic Sciences, Stroke Center, or Neurovascular Research Unit) from the MEDLINE data base, we searched the Internet home page of the institution to obtain additional information. For the purpose of our research, the country of the first author was considered the country of origin of the article. If the first author was affiliated with $>1$ country, the corresponding author's country was considered the country of origin of the article.

The journals in which articles were published were classified as neuroscience journals, radiology journals, and journals related to other medical specialties (including multidisciplinary journals). Neuroscience journals were considered those that were included under the subject category "Clinical Neurology" or "Neurosciences" on the Web of Knowledge Journal Citation Reports: Science Edition 2012. ${ }^{4}$ The journals included under the subject category "Radiology, Nuclear Medicine and Medical Imaging" or "Neuro- imaging" were classified as radiology journals. According to the Journal Citation Reports, several journals were listed under $>1$ subject category, depending on the content of the journal. Journals that fell into $>1$ category were manually reviewed and assigned to only 1 category on the basis of the title of the journal, information contained in "Instructions to Authors," and the table of contents in a sample issue. For example, the American Journal of Neuroradiology was listed under "Clinical Neurology," "Neuroimaging," and "Radiology, Nuclear Medicine and Medical Imaging" subject categories and was assigned to the radiology journal category.

The IF of each journal was retrieved for the year of publication from the Journal Citation Reports. The IF of a journal for a given year is calculated by the number of citations that year of all articles published in the preceding 2 years divided by the number of articles published in that journal during the same period. ${ }^{5}$ Of note, several journals were not indexed in the Science Citation Index or Science Citation Index (Expanded) and did not have IFs; therefore, any articles from these journals were excluded from the IF analysis.

Four study investigators (J.Y.L, D.Y.Y., S.D.Y., and S.A.N.) initially reviewed the same 200 articles independently to ensure consistency of data abstraction. Any disagreements were resolved by a consensus meeting. After initial pilot abstraction, the total number of articles was divided randomly into 4 samples and was manually reviewed by investigators. Questionable cases were decided by consensus of the all study investigators.

\section{Analyses}

The data were downloaded into a spreadsheet for analysis by using Excel software (Microsoft, Redmond, Washington). The present study adopted a descriptive research approach by bibliometric analysis. Relationships between the first author's specialty (radiology, neurosurgery, neurology, or miscellaneous specialties) and evaluated parameters were evaluated by using $\chi^{2}$ or ANOVA tests.

Statistical analyses were performed by using the Statistical Package for the Social Sciences software (Version 12.0 for Windows; IBM, Armonk, New York), and a $P$ value $<.05$ was considered statistically significant.

\section{RESULTS \\ Total Publications}

There were 2123 neurointervention-related articles in the PubMed data base between 2003 and 2012. Our examination of the trend in the number of publications demonstrated slow growth from 2003 to 2012, with an average annual growth rate during the period of $+6.0 \%$ (Fig 1 ).

\section{Type of Documents, Language, Topic, and Funding}

The most frequent type of document was original article $(n=$ $1107,52.1 \%)$. Case reports and review articles numbered 762 $(35.9 \%)$ and $162(7.6 \%)$, respectively. The language of most articles was English ( $n=1948,91.8 \%)$, followed by Japanese $(n=57$, $2.7 \%)$, Chinese $(n=32,1.5 \%)$, and German $(n=22,1.0 \%)$. The most frequent topic was endovascular treatment of aneurysm $(n=941,44.3 \%)$, followed by stent or angioplasty for vascular stenosis $(n=362,17.1 \%)$. During the study period, $192(9.0 \%)$ articles received funding (Table 1). Original articles (168 of 1107, 
$15.2 \%)$ were funded more often than other article types such as technical notes ( 4 of $92,4.3 \%$ ), reviews ( 6 of 162, 3.7\%), and case reports ( 14 of $762,1.8 \%$ ).

\section{Journals}

The 2123 articles were published in 245 journals. Most articles were published in neuroscience journals $(n=1106,52.1 \%)$, followed by radiology journals $(n=703,33.1 \%)$ (Table 1$)$. Table 2 shows the top 20 journals containing articles that focused on neurointervention. The mean journal IF of 1830 ar- ticles published in Scientific Citation Index (Expanded) journals was 2.193 .

The mean journal IF of publications from neurology (3.645) was significantly higher than that observed for radiology (2.103) and neurosurgery (1.806) (Table 3).

\section{Country of Origin and Collaboration}

Researchers from 48 countries published at least 1 article. Researchers from the United States published the most articles $(n=$ $661,31.1 \%)$, followed by Japan $(n=287,13.5 \%)$, China $(n=184$,

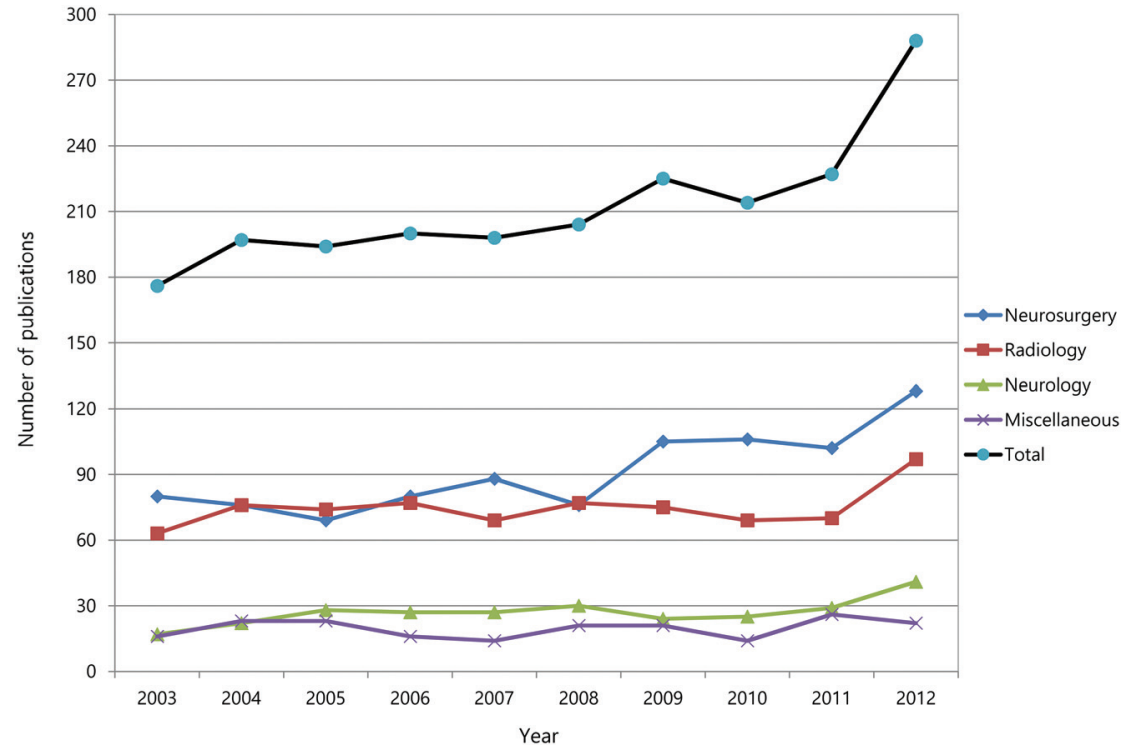

$8.7 \%)$, and South Korea $(n=170,8.0 \%)$ (Table 4). A total of 1060 articles (49.9\%) resulted from collaboration with authors from different departments. Among them, 43 articles were the result of collaboration with a corresponding author from another department and 1017 articles were the result of collaboration with coauthors from other departments (Table 5).

\section{First Author's Specialty and Its Relationship to Other Parameters}

With regard to specialty contribution, neurosurgery departments produced the most articles ( $n=910,42.9 \%)$, followed by radiology $(n=747,35.2 \%)$ and neurology ( $n=270,12.7 \%)$ (Table 1$)$. The average annual growth of publications from neurology $(+17.3 \%)$ was higher than that observed for publications from

FIG 1. Annual amount of neurointerventional research between 2003 and 2012

Table 1: Characteristics of neurointerventional research between 2003 and $2012^{a}$

\begin{tabular}{|c|c|c|c|c|c|}
\hline & \multicolumn{5}{|c|}{ Department of the First Author } \\
\hline & $\begin{array}{l}\text { Neurosurgery } \\
\quad(n=910)\end{array}$ & $\begin{array}{l}\text { Radiology } \\
(n=747)\end{array}$ & $\begin{array}{l}\text { Neurology } \\
(n=270)\end{array}$ & $\begin{array}{l}\text { Miscellaneous } \\
\quad(n=196)\end{array}$ & $\begin{array}{c}\text { Total } \\
(n=2123)\end{array}$ \\
\hline \multicolumn{6}{|l|}{ Document type } \\
\hline Original article & $436(47.9)$ & $429(57.4)^{\mathrm{b}}$ & $140(51.9)$ & $102(52.1)$ & $1107(52.1)$ \\
\hline Case report & $360(39.6)^{c}$ & $236(31.6)$ & $93(34.4)$ & $73(37.2)$ & $762(35.9)$ \\
\hline Review & $59(6.5)$ & $49(6.6)$ & $35(13.0)^{d}$ & $19(9.7)^{\prime}$ & $162(7.6)$ \\
\hline Technical note & $55(6.0)^{e}$ & $33(4.4)$ & $2(0.7)$ & $2(1.0)$ & $92(4.4)$ \\
\hline \multicolumn{6}{|l|}{ Journal } \\
\hline Neuroscience journal & $636(69.9)^{f}$ & $245(32.8)$ & $176(65.2)^{f}$ & $49(25.0)$ & $1106(52.1)$ \\
\hline Radiology journal & $194(21.3)$ & $432(57.8)^{g}$ & $48(17.8)$ & $29(14.8)$ & $703(33.1)$ \\
\hline Other or multidisciplinary journal & $80(8.8)$ & $70(9.4)$ & $46(17.0)$ & $118(60.2)^{g}$ & $314(14.8)$ \\
\hline \multicolumn{6}{|l|}{ Topic } \\
\hline Endovascular treatment of aneurysm & $481(52.9)^{\mathrm{g}}$ & $357(47.8)$ & $39(14.4)$ & $64(32.7)$ & $941(44.3)$ \\
\hline Stent or angioplasty for vascular stenosis & $120(13.2)$ & $111(14.9)$ & $72(26.7)^{d}$ & $59(30.1)^{d}$ & $362(17.1)$ \\
\hline Endovascular treatment of AVM or AVF & $174(19.2)^{\mathrm{e}}$ & $145(19.4)^{\mathrm{e}}$ & $13(4.8)$ & $23(11.6)$ & 355 (16.7) \\
\hline Thrombolysis or thrombectomy & $65(7.1)$ & $93(12.4)$ & $131(48.5)^{g}$ & $26(13.3)$ & $315(14.8)$ \\
\hline Vasospasm & $23(2.5)$ & $15(2.0)$ & $3(1.1)$ & $7(3.6)$ & $48(2.3)$ \\
\hline Tumor embolization & $23(2.5)$ & $6(0.8)$ & $1(0.4)$ & $2(1.0)$ & $32(1.5)$ \\
\hline General or miscellaneous & $24(2.6)$ & $20(2.7)$ & $11(4.1)$ & $15(7.7)^{\mathrm{d}}$ & $70(3.3)$ \\
\hline \multicolumn{6}{|l|}{ Declared funding } \\
\hline Funded & $62(6.8)$ & $65(8.7)$ & $41(15.2)^{d}$ & $24(12.2)$ & $192(9.0)$ \\
\hline Not funded & $848(93.2)$ & $682(91.3)$ & $229(84.8)$ & $172(87.8)$ & $1931(91.0)$ \\
\hline
\end{tabular}

a Numbers in parentheses are percentages.

${ }^{b}$ Significantly different from the value for neurosurgery.

' Significantly different from the value for radiology.

d Significantly different from the values for departments of neurosurgery and radiology.

e Significantly different from the values for departments of neurology and miscellaneous.

${ }^{f}$ Significantly different from the values for departments of radiology and miscellaneous.

${ }^{\mathrm{g}}$ Significantly different from the values for all other departments. 
neurosurgery $(+7.4 \%)$ and radiology $(+5.9 \%)$ (Fig 1$)$.

The document type varied slightly from specialty to specialty. Neurosurgeons published more case reports than did radiologists and more technical notes than neurologists and miscellaneous researchers. Radiologists published more original articles than neurosurgeons did, whereas neurologists published more review articles than neurosurgeons and radiologists. Three major departments published more than half (57.8\%-69.9\%) of the articles in their own specialty journals (Table 1).

Contributions from departments also differed widely according to the country of origin. For instance, neurosurgery was the most productive department for research in the top 4 most productive countries (United States, Japan, China, and South Korea). In most other countries, however, radiologists were the greatest contributors (Table 4).

Table 5 shows the pattern of collaboration among departments. Departments of neurology (65.6\%) demonstrated significantly higher rates of interdisciplinary collaboration than departments of radiology (53.1\%) and neurosurgery (41.3\%).

\begin{tabular}{|c|c|c|c|}
\hline Rank & Journal & $\begin{array}{c}\text { Mean } \\
\text { Journal } \\
\text { IF }^{\mathrm{a}}\end{array}$ & $\begin{array}{l}\text { No. of } \\
\text { Articles }\end{array}$ \\
\hline 1 & American Journal of Neuroradiology & 2.778 & 233 \\
\hline 2 & Interventional Neuroradiology & 0.341 & 173 \\
\hline 3 & Neurosurgery & 2.802 & 165 \\
\hline 4 & Neuroradiology & 2.064 & 109 \\
\hline 5 & Journal of Neurosurgery & 2.511 & 104 \\
\hline 6 & Stroke & 5.971 & 84 \\
\hline 7 & Journal of Neurointerventional Surgery & $1.123^{b}$ & 71 \\
\hline 8 & $\begin{array}{l}\text { Surgical Neurology or World } \\
\text { Neurosurgery }\end{array}$ & 1.195 & 57 \\
\hline 9 & Neurologia Medico-Chirurgica (Tokyo) & 0.548 & 43 \\
\hline 10 & No Shinkei Geka (Japanese) & - & 42 \\
\hline 11 & Acta Neurochirurgica (Wien) & 1.323 & 41 \\
\hline 12 & Journal of Clinical Neuroscience & 0.973 & 39 \\
\hline 13 & Journal of Neuroimaging & 1.421 & 31 \\
\hline 14 & Journal of Korean Neurosurgical Society & $0.481^{d}$ & 28 \\
\hline 15 & Neurosurgical Focus & $2.567^{\mathrm{b}}$ & 27 \\
\hline 16 & Neurology India & 0.696 & 23 \\
\hline 16 & Zhonghua Nei Ke Za Zhi (Chinese) & - & 23 \\
\hline 16 & Neurological Research & 1.432 & 23 \\
\hline 19 & $\begin{array}{l}\text { Journal of Vascular and Interventional } \\
\text { Radiology }\end{array}$ & 2.133 & 21 \\
\hline 19 & Minimally Invasive Neurosurgery & 0.731 & 21 \\
\hline
\end{tabular}

a Mean journal Impact Factor between 2003 and 2012.

${ }^{\mathrm{b}}$ Mean journal Impact Factor between 2010 and 2012.

'Surgical Neurology (2003-2009) is the former name of World Neurosurgery (2010-2012).

${ }^{\mathrm{d}}$ Mean journal Impact Factor between 2009 and 2011.

\section{DISCUSSION}

The field of neurointerventional therapy was developed originally in 1960 when Lussenhop, a neurosurgeon, and Spence ${ }^{6}$ described the technique of intravascular embolization of brain AVMs by injecting Silastic spheres (Dow Corning, Auburn, Michigan) through a surgically exposed carotid artery. After this monumental effort, neurointerventional therapy has made tremendous progress in recent years. This progress is attributable to continuing advances in imaging modalities, catheters and other devices, and interventional techniques, coupled with recent pharmaceutical and basic science knowledge. At least until the end of the 1990s, there was a bitter turf war regarding which of 3 specialties, neurosurgery, neuroradiology, and neurology, had the right to practice the neurointerventional procedures.

In the future, however, the most appropriate type of physician to perform the procedure in this evolving subspecialty may become less relevant with the ultimate goal of optimized patient care. In 2006, the Accreditation Council for Graduate Medical Education announced the revised program requirements in the United States for fellowship education in endovascular surgical neuroradiology. ${ }^{7}$ Endovascular surgical neuroradiology occupies a unique niche in the area of neurovascular interventions among neuroradiology, neurosurgery, and neurology. In 2007, after much work, the Society of Neurointerventional Surgery (formerly the American Society of Interventional and Therapeutic Neuroradiology) was formed, comprising all specialists interested in neurointervention. ${ }^{8}$ At present, in many neurointerventional centers throughout the world, clinical practice and research are performed by the collaborative effort among physicians with different backgrounds of training.

Given the relatively less invasive nature, rapid technical advances, and the large number of patients, neurointerventional therapy of cerebrovascular disease promises to be a greatly expanding field across many specialty disciplines such as neurosurgery, radiology, and neurology. Therefore, determining the group of physicians most appropriate to perform this specific endovascular procedure is becoming more difficult. ${ }^{9-11}$

The results of our study show that the total number of publications has slightly increased from 2003 to 2012. This increase in publications seems to be related to the increasing worldwide prevalence of cerebrovascular diseases and the increasing interest in the neurointerventional treatment from multiple disciplines. The most active discipline was neurosurgery, but we also observed increases in publications from radiology and neurology.

Despite these achievements, there were 2 disappointing features in the publications that focused on the neurointerventional

Table 3: Impact Factor of journals that published neurointerventional research between 2003 and 2012

\begin{tabular}{|c|c|c|c|c|}
\hline & \multicolumn{4}{|c|}{ Department of the First Author } \\
\hline & Neurosurgery & Radiology & Neurology & Miscellaneous \\
\hline No. of articles published in $\mathrm{SCl}(\mathrm{E})$-indexed journals & 760 & 688 & 240 & 142 \\
\hline No. of SCI(E)-indexed journals & 150 & 59 & 30 & 54 \\
\hline Mean journal IF & $1.806 \pm 1.549$ & $2.103 \pm 2.027$ & $3.645 \pm 5.259^{a}$ & $2.245 \pm 1.826$ \\
\hline 25th Percentile Journal IF & 0.645 & 1.069 & 1.378 & 1.057 \\
\hline 50th Percentile (median) journal IF & 1.274 & 1.990 & 2.244 & 2.135 \\
\hline 75th Percentile journal IF & 2.517 & 2.629 & 4.900 & 2.856 \\
\hline
\end{tabular}

Note:- $\mathrm{SCI}(\mathrm{E})$ indicates Scientific Citation Index (Expanded).

a Significantly different from values for all other departments. 
therapy of cerebrovascular diseases. First, only approximately half of the publications were in the form of original articles. This disproportionately low number of original articles suggests that increases in publication may not necessarily be accompanied by an equivalent increase in the growth of the global scientific impact. Second, only $9.0 \%$ of all publications received funding. It is possible that the preponderance of case reports and review articles are reducing the percentage of funded articles because these articles are not usually funded. When examining the original articles specifically, $15.2 \%$ of published original articles received funding. This funding rate is substantially lower than that in several other specialties, such as interventional radiology $(23.0 \%)^{12}$ and general radiology $(26.9 \%) .{ }^{13}$ These findings are alarming, given that a positive relationship between funding and research productivity has been well established. ${ }^{14}$

The United States was the leading country in producing articles on neurointervention, contributing $31.1 \%$ of the publications. This relative contribution of the United States is less than that in radiology literature $(45.5 \%) .{ }^{13}$ However, our figure is similar to the productivity in neurosurgery $(31.7 \%)$ and stroke $(27.2 \%)$ research of the United States. ${ }^{15,16}$ Three Far East Asian
countries-Japan, China, and South Korea-collectively accounted for $30.2 \%$ of publications. Although the cause of the high research productivity from these countries is likely multifactorial, state-of-the-art equipment and high standard training and education programs in these countries are possible key forces in this achievement.

An interesting feature of our study was that 3 major departments published a relatively small portion $(57.8 \%-69.9 \%)$ of articles in their own specialty journals. We surmise that most journals related to neurointervention have an open spirit, providing a publication opportunity for researchers from other disciplines. One of the current trends in scientific publication is publication across disciplines. Several recent studies have addressed the evolution of the departmental affiliations of primary authors in many disciplines. ${ }^{17-19}$

Another interesting finding of the study was that half of the publications were the result of interdisciplinary collaboration. Although little attention has been paid to interdisciplinary collaboration in medical research, research on the neurointerventional therapy of cerebrovascular disease can be classified as a high-collaboration area at the specialty level. Many possible explanations exist for this interesting finding. First, some of these authors might even have multiple backgrounds or different specialties. The senior or corresponding author is often the person who plays the most important role on the research team. Second, interdisciplinary collaboration in research may reflect interdisciplinary collaboration in clinical practice for the neurointerventional therapy of cerebrovascular disease. However, it is unclear how many neurointerventional procedures are currently performed by each specialty. Finally, the size of the research group is increasing on all levels - the total number of authors, departments, institutions, and countries. The large research group has clear advantages for funding and other resources in biomedical research. ${ }^{20}$

Although the results of our study revealed that neurosurgeons, radiologists, and neurologists contributed in important ways to publications relating to neurointervention, we found several in-

Data in

b Includes articles originating from Hong Kong.

Table 5: Collaboration with other disciplines in neurointerventional research between 2003 and $2012^{\mathrm{a}}$

\begin{tabular}{|c|c|c|c|c|c|}
\hline \multirow[b]{2}{*}{ Collaboration Type } & \multicolumn{5}{|c|}{ Department of the First Author } \\
\hline & $\begin{array}{l}\text { Neurosurgery } \\
(n=910)\end{array}$ & $\begin{array}{l}\text { Radiology } \\
(n=747)\end{array}$ & $\begin{array}{l}\text { Neurology } \\
(n=270)\end{array}$ & $\begin{array}{l}\text { Miscellaneous } \\
(n=196)\end{array}$ & $\begin{array}{c}\text { Total } \\
(n=2123)\end{array}$ \\
\hline Collaboration with other disciplines & $376(41.3)$ & $397(53.1)$ & $177(65.6)^{b}$ & $110(56.1)$ & $1060(49.9)$ \\
\hline Corresponding author from other disciplines & $17(1.9)$ & $7(0.9)$ & $10(3.7)$ & $9(4.6)$ & $43(2.0)$ \\
\hline $\begin{array}{l}\text { 1) Coauthors from neurosurgery, radiology, and/or } \\
\text { neurology disciplines }\end{array}$ & $264(29.0)$ & $287(38.4)$ & $107(39.6)$ & $65(33.2)$ & $723(34.1)$ \\
\hline 2) Coauthors from other disciplines & $57(6.3)$ & $52(7.0)$ & $26(9.6)$ & $25(12.8)$ & $160(7.5)$ \\
\hline $1+2$ & $38(4.2)$ & $51(6.8)$ & $34(12.6)$ & $11(5.6)$ & $134(6.3)$ \\
\hline No collaboration with other disciplines & $534(58.7)$ & $350(46.9)$ & $93(34.4)$ & $86(43.9)$ & $1063(50.1)$ \\
\hline
\end{tabular}

${ }^{a}$ Data in parentheses are percentages.

b Significantly different from values for all other departments. 
teresting differences in the publication pattern among specialties.

First, radiologists produced more original articles, neurosurgeons published more case reports and technical notes, and neurologists published more review articles. In addition, neurologists published their findings in journals with higher Impact Factors. Although it may be tempting to conclude that neurologists' research is superior to that of radiologists and neurosurgeons and, thus, is accepted by more prestigious journals, an alternative explanation is that neurologists published more articles in multidisciplinary journals that have more readers and higher journal IFs. Second, the funding rate of neurology (15.2\%) was significantly higher than that observed for radiology $(8.7 \%)$ and neurosurgery $(6.8 \%)$. The exact cause of this disparity in funding is unclear and is likely multifactorial. Third, the specialty of the authors who published articles on this topic varied according to the country of origin. For instance, most articles originating from the top 4 most productive countries were published by neurosurgeons. Different national patterns of research output may indicate different clinical practice patterns if research precedes clinical adoption. Last, our results showed more collaboration in publications by first authors affiliated with departments of neurology (65.6\%) than those affiliated with departments of radiology (53.1\%) and neurosurgery $(41.3 \%)$. A possible explanation for this finding may relate to the staff composition of neurointerventional centers. Neurologists may be a rather small group in the research team or may have a less prominent role in clinical research.

Several limitations in interpreting the results of this bibliometric study should be kept in mind. First, this study is limited to only articles indexed within the PubMed data base, which does not index all research. While PubMed is generally considered a comprehensive and trusted resource, any bias in PubMed indexing of articles could have potentially influenced the results. Second, it is difficult to identify publications that focus on neurointervention because of its broad nature and varied terminology. Consequently, some articles pertaining to the neurointerventional treatment of cerebrovascular disease may have been excluded accidentally. However, the goal of this study was not to capture all neurointerventional research but rather to examine a large representative sample. Finally, the assignment of the clinical specialty and country was based on the affiliation of the first author. Many publications in our data are the product of a collaborative effort among different specialties or countries, so assigning articles to 1 specialty or country is inherently difficult. However, several studies ${ }^{21,22}$ have determined that first authors make the greatest contributions to the research and are considered the best means of assigning credit.

\section{CONCLUSIONS}

Even though the bibliometric methodology used may present some limitations, our bibliometric analysis provides a pivotal tool to evaluate the characteristics and trends of the publications related to the neurointerventional treatment of cerebrovascular diseases. Neurosurgery, radiology, and neurology have contributed substantially to research on neurointervention, though they each showed slightly different patterns of publication. Slow growth, high interdisciplinary collaboration, and a low level of funding are peculiar characteristics of research in this field.

\section{REFERENCES}

1. World Health Organization. Media Centre. The ten top causes of death. http://www.who.int/mediacentre/factsheets/fs310/en/index. html. Accessed October 15, 2013

2. Wakhloo AK, Deleo MJ 3rd, Brown MM. Advances in interventional neuroradiology. Stroke 2009;40:e305-12

3. Luukkonen T. Bibliometrics and evaluation of research performance. Ann Med 1990;22:145-50

4. Web of Science. Journal Citation Reports: Science Edition 2012. http:// wokinfo.com/media/pdf/qrc/jcrqrc.pdf. Accessed October 20, 2013

5. Garfield E. The history and meaning of the journal impact factor. JAMA 2006;295:90-93

6. Lussenhop AJ, Spence WT. Artificial embolization of cerebral arteries: report of use in a case of arteriovenous malformation. $\mathrm{JAm}$ Med Assoc 1960;172:1153-55

7. Accreditation Council for Graduate Medical Education. ACGME Program Requirements for Graduate Medical Education in Endovascular Surgical Neuroradiology. http://www.acgme.org/acgmeweb/ Portals/0/PFAssets/2013-PR-FAQ-PIF/163-182-422_endovascular_ neuroradiology_07012013_1-YR.pdf. Accessed October 20, 2013

8. Society of Neurointerventional Surgery. http://www.snisonline.org/. Accessed October 20, 2013

9. Higashida RT. Evolution of a new multidisciplinary subspecialty: interventional neuroradiology/neuroendovascular surgery. AJNR Am J Neuroradiol 2000;21:1151-52

10. Levy EI, Rinaldi MJ, Howington JU, et al. Should interventional cardiologists treat ischemic strokes? A global perspective. J Invasive Cardiol 2002;14:646-51

11. Johnston SC. Who belongs inside the carotid arteries? Neurology 2005;64:188-89

12. Ray CE Jr, Gupta R, Blackwell J. Changes in the American interventional radiology literature: comparison over a 10-year time period. Cardiovasc Intervent Radiol 2006;29:599-604

13. Lim KJ, Yoon DY, Yun EJ, et al. Characteristics and trends of radiology research: a survey of original articles published in AJR and Radiology between 2001 and 2010. Radiology 2012;264:796-802

14. Lyubarova R, Itagaki BK, Itagaki MW. The impact of National Institutes of Health funding on U.S. cardiovascular disease research. PLoS One 2009;4:e6425

15. Hauptman JS, Chow DS, Martin NA, et al. Research productivity in neurosurgery: trends in globalization, scientific focus, and funding. J Neurosurg 2011;115:1262-72

16. Chow DS, Hauptman JS, Wong TT, et al. Changes in stroke research productivity: a global perspective. Surg Neurol Int 2012;3:27

17. Garg AX, Iansavichus AV, Kastner M, et al. Lost in publication: half of all renal practice evidence is published in non-renal journals. Kidney Int 2006;70:1995-2005

18. Donovan AJ, Tompkins RK. Surgical research publication in a selection of research and surgical specialty journals. Surgery 2010; 147:5-12

19. Yun EJ, Yoon DY, Kim BY, et al. Where do radiologists publish their work? A comparative analysis of publications by radiologists in nonradiology journals in 2000 and 2010. AJR Am J Roentgenol 2013;200:W560-65

20. Engels TCE, Goos P, Dexters N, et al. Group size, h-index, and efficiency in publishing in top journals explain expert panel assessments of research group quality and productivity. Res Eval 2013;22:224-36

21. Slone RM. Coauthors contributions to major papers published in the AJR: frequency of undeserved coauthorship. AJR Am J Roentgenol 1996;167:571-79

22. Hwang SS, Song HH, Baik JH, et al. Researcher contributions and fulfillment of ICMJE authorship criteria: analysis of author contribution lists in research articles with multiple authors published in radiology-International Committee of Medical Journal Editors. Radiology 2003;226:16-23 